\title{
The Study on the Problem of the Relationship between the "Heterogeneity" of the Neighbor Enterprise and the Financing Efficiency of SMEs in China
}

\section{-Empirical Data from China Industrial Enterprises Database}

\author{
Ruohuan He \\ Jinan University, College of Economics, Guangzhou, China \\ Email: 1845691121@qq.com
}

How to cite this paper: He, R.H. (2017) The Study on the Problem of the Relationship between the "Heterogeneity" of the Neighbor Enterprise and the Financing Efficiency of SMEs in China. Open Journal of Applied Sciences, 7, 171-183.

https://doi.org/10.4236/ojapps.2017.74015

Received: March 10, 2017

Accepted: April 27, 2017

Published: April 30, 2017

Copyright $\odot 2017$ by author and Scientific Research Publishing Inc. This work is licensed under the Creative Commons Attribution International License (CC BY 4.0).

http://creativecommons.org/licenses/by/4.0/

\section{(c) (i) Open Access}

\begin{abstract}
This article tries to introduce the perspective of the "heterogeneity" of the neighbor enterprise into the research on the problem of the financing efficiency of the small and medium sized enterprises (SMEs). It takes enterprises in the China industrial enterprises database from 2005 to 2007 as the object of the research and defines the neighbor enterprise at a town (village, street) scale. This article selects the financing efficiency, enterprise scale, technical innovation of enterprise as the indexes to measure the "heterogeneity" of the neighbor enterprise, and examines whether they have a significant relationship with the enterprises themselves or not. Through building panel data model and the empirical analysis, this article finds that the financing efficiency and the degree of technological innovation of the neighbor enterprise are positively related to the financing efficiency of enterprises themselves, and the scale of the neighbor enterprise has a negative correlation with the financing efficiency of enterprises themselves. What's more, this paper distinguishes the neighbor enterprise from the industry unusual neighbor according to whether enterprises are belong to the same industry or not at the same town(village, street), finding the neighbor enterprises which are the same industry have a great more relationship with the financing efficiency of SMEs than the neighbor enterprises which are the non trade.
\end{abstract}

\section{Keywords}

Small and Medium Sized Enterprises, Financing Efficiency,

"Heterogeneity" 


\section{Introduction}

As one of the most active factors in the Socialist Market Economy, SMEs have become a significant force for boosting economy, expanding employment, readjusting the economic structure, fostering the innovation and forming a new industrial chain. However, SMEs' development has been constrained by financing difficulties, and in the final analysis, financing difficulties are the problem of low financing efficiency.

As the saying goes, "A near neighbor is better than a distant cousin". For people, the saying is right, the same to SMEs. In real life, as human beings, we have a very close relationship with our neighbors while SMEs are bound up with their neighbors. As the individual of neighbors will affect each other, which in social psychology called "neighborhood effect". Through observation, it is not difficult to find that the financing efficiency of SMEs is not only related to their own endowment, but also related to the neighbor enterprise. In recent years, many scholars have focused on the theory of heterogeneous enterprises. From the point of view of statistics, heterogeneity refers to the difference between the sample and the observed individual. Homogenization is what that we can not to distinguish the difference of it easily. "Heterogeneity" is not often observed in everyday life, but as the opposite of "homogenization", it always appears with the well-known "homogenization". "Heterogeneity" exists widely in many subjects, such as Ecology [1], Building science and Engineering [2], Economics [3], Psychiatry [4], Investment [5] and so on. And the relationship between the "heterogeneity" of the neighbors and the financing efficiency of SMEs in China is worth exploring. Research on the financing efficiency of SMEs has always been a hot topic in academia, however, the research mainly focuses on the definition of financing efficiency, the evaluation method of financing efficiency and the way to solve the financing efficiency. The ways to improve the financing efficiency mainly include the small and medium-sized enterprises themselves, the banking system reform, the government support, heterogeneity of entrepreneurs. So far, a few of scholars have studied the problem of "heterogeneity" and the financing efficiency of SMEs. Therefore, it provides a perspective for the study of this paper, that is to study the problem of the relationship between the "heterogeneity" of the neighbor enterprise and the financing efficiency of SMEs in China.

\section{Influence Mechanism}

\subsection{Mechanism of Knowledge-Spillover Effect}

Marx once pointed out: "productivity also includes science and the development of fixed capital indicates that to a large extent, the general social knowledge has become a direct productive force". This is consistent with the view that the fundamental driving force of national economic growth is the growth and accumulation of knowledge in the New Economic Growth Theory. And as a kind of resources, knowledge is inherently non-competitive and partly non-exclusive at the same time. These two properties determine that knowledge-spillover effect 
does exist. Knowledge is divided into explicit knowledge and tacit knowledge, explicit knowledge is very easy to spread, diffuse, copy while the spread, diffusion and copy of tacit knowledge are faced with more stringent restrictions. These restrictions, to some extent, determine that tacit knowledge can only be transmitted within a certain geographical area, so individuals of the neighbors have the opportunity to communicate and learn from each other. Kesidou (2004) argues that local knowledge spillovers have obvious technical externality, that is, Enterprise A can use the new knowledge or new technology created by Enterprise B for free. As a result, geographical proximity makes it easy for the neighbors to obtain the specific investment, skilled labor, information, system and public goods, and to benefit from complementary activities. Cassar and Nicolini (2003) [6] examine the influence of localized Technology Spillover Effects on growth, and their work showed that geographical proximity can help enterprises to form positive spillover effect and improve the possibility of successful innovation, so as to promote the productivity of each other and the overall local economic growth. Patrick (1966) [7] believes that financial deepening and development are in a "demand-compliance" state relative to economic growth. $\mathrm{He}$ also thinks that financial deepening and development are attached to economic growth. And financial deepening and development will inevitably diversify the financing channels, which can make enterprises choose the most suitable financing model or finance at the lowest cost when enterprises need to finance. This will undoubtedly improve the financing efficiency of SMEs.

\subsection{Information Sharing Mechanism}

Information is one of the decisive factors whether the fund providers are willing to provide funds to the fund demanders. At the present, many scholars have studied the asymmetric information of the finance. There will be full of the phenomenon of the asymmetric information in the SME financing. And the asymmetric information always lead to adverse selection and moral hazard why the fund providers are not willing to provide funds to the fund demanders. At a result, SMEs have the problem of low financing efficiency. Generally speaking, the gathering of SMEs and the neighbor enterprise in space will build a "mutual knowledge" society. Liu Ke and Wang Lan et al. [8] think that communication between business managers will promote the information of the reputation of the enterprise and the quality of the assets of the enterprise to spread in this "mutual knowledge" society, and this will expand the channels of information exchange between enterprises and fund providers. The information sharing mechanism mainly affect the financing efficiency of SMEs through the following two ways. On the one hand, social relationships are built among enterprise executives. On the other hand, the cooperative partnership are built among the SMEs. So the information sharing mechanism can make the information about SMEs are got quickly so that it can shorten the time for SMEs to obtain a loan. And it will improve the financing efficiency of SMEs. 


\section{Research Hypothesis}

Through the above analysis of the influence mechanism, this paper finds that the mechanism of knowledge-spillover effect and the information sharing mechanism will improve the financing efficiency of SMEs. What's more, not only does the financing efficiency of SMEs has relations with their factor endowments that include the Total Assets Turnover, the Long-term liability rate, the main business cost margins, etc., but also has relations with the heterogeneity of the neighbor enterprise, in some way. The heterogeneity of the neighbor enterprise is divided into the financing efficiency, the enterprise scale, the technological innovation and whether they are the same industry in this paper. So in this section, this paper presents four hypotheses. The relationship of the financing efficiency between the neighbor enterprises and the SMEs, the relationship between the enterprise scale of the neighbor enterprise and the financing efficiency of the SMEs, the relationship between the technological innovation of the neighbor enterprise and the financing efficiency of the SMEs, the relationship between the same industry or the non trade that the neighbor enterprise are and the financing efficiency of the SMEs, respectively.

\subsection{Hypothesis 1}

At present, China is in a critical period of economic transition, so the development of SMEs has a great impact on the process of economic restructuring. The development of SMEs mainly depend on the ability of financing that is the key to SMEs. Wang Xi-qin and Tang Zi-bin et al. [9] find that the key factor of the effective allocation of the financial resources is to solve the problem of asymmetric information. Helsley and Strange et al. [10] believe that as a geographical neighbor, frequent exchanges between enterprises will become possible. Therefore, this paper thinks that as a geographical neighbor, the frequent exchanges between enterprises will undoubtedly increase the diffusion and communication of the information. The improvement of the financing efficiency of the neighbor enterprises is the result of the more transparent information. So the transparency of information can promote the financing efficiency of SMEs.

According to the above analysis, this paper makes the hypothesis 1: the more higher the financing efficiency of the neighbor enterprises (The average of the financing efficiency of neighbor Enterprises) is, the more higher the financing efficiency of SMEs.

\subsection{Hypothesis 2}

Jalilvand and Harris et al. [11] think that enterprise which has a relatively large scale has small problems in the asymmetric information and agency and has a inherent advantage in long term debt market. So this paper thinks that the enterprise scale of the neighbor enterprise has a relationship with the financing efficiency of SMEs. Wei Kai-wen et al. [12] thinks that because debt financing faces various risks that the company can not discharge its liabilities when due, the financing efficiency of SMEs will drop. As a result, if the enterprise scale of the 
neighbor enterprise is relatively large, the financing efficiency of SMEs will drop in some degree.

According to the above analysis, this paper makes the hypothesis 2: the more higher the enterprise scale of the neighbor enterprises (The average of the enterprise scale of neighbor Enterprises) is, the more higher the financing efficiency of SMEs.

\subsection{Hypothesis 3}

In the age of knowledge economy, the technological innovation has become a key driver of economic growth. Joseph Alois Schumpeter put forward Innovation "Theory" for the first time in the book "Theory of Economic Development". He thinks that the technological innovation plays a great role in promoting economic development. And this view has been proved in the long history of economic development. Robert M. Solow et al. [13] and other foreign scholars have expounded the relationship between technological innovation and economic growth, and a large number of domestic scholars have confirmed that there is a significant positive relationship between technological innovation and economic growth, such as Liu Hong and Yao Yong-ling et al., Li Zheng-hui and Xu Wei et al. [14] [15]. So this paper believes that the improvement of the technology innovation of the neighbor enterprise will promote the economic growth of the town. Patrick believes that financial deepening and development are in a "demand-compliance" state relative to economic growth, and Robinson and Stern also believe the above view. Therefore, the technological innovation of enterprises in this town will lead to a diversification of financing channels.

According to the above analysis, this paper makes the hypothesis 3: the more higher the technological innovation of the neighbor enterprises(The average of the technological innovation of neighbor Enterprises) is, the more higher the financing efficiency of SMEs.

\subsection{Hypothesis}

If there is a certain relationship between the financing efficiency of SMEs and the neighbor enterprise, which relationship would be more significant, the same industry or the non trade. When the study which are represented by MAR shows that the knowledge-spillover effect of the neighbor enterprise that are at the industry has a great more promoting effect on regional innovation, the study which are represented by Jacobs shows that the knowledge-spillover effect of the neighbor enterprise that are at the diversify industry has a great more promoting effect on regional innovation. Since the 70s of last century, it has become the focus of controversy that the specialization or diversification of industry plays a leading role in promoting the economic growth of China. Bo Wen-guang [16] finds that the diversification of industry plays a leading role in promoting industrial growth, While Zhao Jian-ji and Zeng Gang et al. [17] find that the specialization of industry has a significant positive correlation with industrial growth. This paper holds the view as Zhao Jian-ji and Zeng Gang. 
According to the above analysis, this paper makes the hypothesis 4: the neighbor enterprises which are the same industry have a great more relationship with the financing efficiency of SMEs than the neighbor enterprises which are the non trade.

\section{Model, Data}

This section mainly construct the model of this paper and explain the data.

\subsection{Concept Definition}

The knowledge-spillover effect has a great relationship with the position of the knowledge recipient and the new knowledge source. Wang Zheng et al. [18] find that there is an obvious distance decay regularity in the knowledge-spillover effect. Therefore, in the study of the relationship between "heterogeneity" of the neighbor enterprise and the financing efficiency of SMEs, geographical proximity should be as small as possible. Funke M. , Niebuhr A. [19] finds that the positive correlation between the main body of knowledge spillover and the innovation activities of other enterprises decreased by $50 \%$ every 23 to $30 \mathrm{~km}$. This distance is close to the classification of the town (township, street) level of China's administrative divisions. Therefore, this paper regards the town (township, street) as a research unit.

\subsection{Model}

This section develops a simple model to study the relationship between "heterogeneity" of the neighbor enterprises and the financing efficiency of SMEs in China.

$$
\begin{aligned}
\mathrm{Fe}_{i t}= & \alpha_{0}+\beta_{1} T T_{i t}+\beta_{2} \text { Cost }_{i t}+\beta_{3} L R_{i t}+\gamma_{1} \overline{F e}_{i t}+\gamma_{2} \overline{\operatorname{Size}}_{i t} \\
& +\gamma_{3} \overline{R \& D}_{i t}+\theta_{1} \text { Control }_{i t}+\varepsilon_{i t}
\end{aligned}
$$

$F e_{i t}$ is the financing efficiency of SMEs, and $F e_{i t}=R O I / W A C$ Ratio. $T T_{i t}$ is the Total Assets Turnover, Cost ${ }_{i t}$ is the the main business cost margins, $L R_{i t}$ is the Long-term liability rate, Size ${ }_{i t}$ is the the enterprise scale which is presented by the total assets, $R \& D_{i t}$ is the technological innovation of the enterprise which is presented by Research and development cost/Operating costs. $\overline{F e}_{i t}$ is the financing efficiency of the neighbor enterprises, and

$$
\overline{F e}_{i t}=\left(\sum_{j=1}^{n} F e_{j t}-F e_{i t}\right) /(n-1)
$$

$\overline{\text { Size }}_{i t}$ is the enterprise scale of the neighbor enterprises, and

$$
\overline{\text { Size }}_{i t}=\left(\sum_{j=1}^{n} \text { Size }_{j t}-\text { Size }_{i t}\right) /(n-1)
$$

$\overline{R \& D}_{i t}$ is the technological innovation of the neighbor enterprises, and

$$
{\overline{R \& D_{i t}}}_{i=}\left(\sum_{j=1}^{n} R \& D_{j t}-R \& D_{i t}\right) /(n-1)
$$


Control $_{i t}$ is the control variables, such as, enterprise age, enterprise ownership. $\varepsilon_{i t}$ is the random error. The above variables (except for the control variables) are in logarithmic form.

To solve the problem of the relationship between the same industry or the non trade that the neighbor enterprises are and the financing efficiency of SMEs. This paper develops the following model. In this paper, the town (township, street) that has more than $90 \%$ of the enterprises belonging to the same industry is viewed as the same neighbor enterprise town (township, street).

When the neighbor enterprises are at in the same industry,

$$
\begin{aligned}
F_{i t}= & \alpha_{1}+\beta_{21} T T_{i t}+\beta_{22} \operatorname{Cost}_{i t}+\beta_{23} L_{i t}+\gamma_{21} \overline{F e}_{i t} \\
& +\gamma_{22} \overline{\operatorname{Size}}_{i t}+\gamma_{23} \overline{R \& D}_{i t}+\theta_{21} \text { Control }_{i t}+\varepsilon_{i t}
\end{aligned}
$$

When the neighbor enterprises are at in the non trade

$$
\begin{aligned}
F_{i t}= & \alpha_{2}+\beta_{31} T T_{i t}+\beta_{32} \operatorname{Cost}_{i t}+\beta_{33} L R_{i t}+\gamma_{31} \overline{F e}_{i t} \\
& +\gamma_{32} \overline{\operatorname{Size}}_{i t}+\gamma_{33} \overline{R \& D}_{i t}+\theta_{31} \text { Control }_{i t}+\varepsilon_{i t}
\end{aligned}
$$

Table 1 shows the relative variables.

\subsection{Data}

This paper mainly select the annual survey of China industrial enterprises database as the data source. And this paper mainly use the total assets of the enterprise, the sales revenue, the main business costs, research and development costs, long-term liabilities and other data. However, in order to maintain the continuity of the data, this paper mainly select the China industrial enterprises database from 2005 to 2007 as the research object. Due to the data of the annual survey data of China industrial enterprise database from 2005 to 2007 is relatively rough, this paper eliminates some data. Such as, eliminating the number of employees less than 10 people, the enterprise in the non operating state etc. This paper regards the enterprise which the first 9 business registration code is same as belonging to the same town (township, street). The amount of data used in this paper is huge, and the panel data can reduce the endogenous problem in some ways. Therefore, the empirical study of this paper has some credibility.

\section{Empirical Evidence}

This section presents the empirical examination of the above four hypotheses using the data of the annual survey data of China industrial enterprise database from 2005 to 2007. Based on the above the data selection method, this paper finally selects 1966 towns (towns, streets) as the sample data which are used to study the problem of the relationship between the "heterogeneity" of the neighbor enterprise and the financing efficiency of SMEs in china.

The regression results are shown in the following Table 2 for the regression of the basic model (1).

\subsection{Empirical Evidence for the Hypothesis 1}

According to the regression results of Table 1, this paper can find that the aver- 
age of the financing efficiency of the neighbor enterprise is increased by about $1 \%$, and the financing efficiency of SMEs is increased by a factor of $0.51 \%$ from the regression (1). This means that there is a positive correlation between the financing efficiency between the neighbor enterprise and SMEs, that is, this paper verifies the hypothesis 1 . This conclusion is consistent with the study of some scholars in China. Kang Jing and Wang $\mathrm{Na}$ [20] believe that the financing of SMEs cluster can obtain scale effect and multiplier effect, and because SMEs cluster makes the region's economic growth accelerate, capital accumulation faster, the multiplier effect of release of the loan is great, so repeated. Wei Shouhua et al. [21] thinks that the SMEs cluster has a unique advantage in indirect finance because the SMEs cluster can increase the information symmetry between banks and enterprises and reduce transaction costs. Therefore, on the one hand, the rapid growth of the local economy makes the money multiplier of financial institution expand. On the other hand, the communication between enterprises is more frequent and the information flow is more convenient because of the neighbouring geographical position of SMEs. At a result, the cost of obtaining information for SMEs by bank will be reduced.

To summarize, the more higher the financing efficiency of the neighbor enterprises (The average of the financing efficiency of neighbor Enterprises) is, the more higher the financing efficiency of SMEs.

\subsection{Empirical Evidence for the Hypothesis 2}

According to the regression results of Table 1, this paper can find that the ave-

Table 1. Main variable description.

\begin{tabular}{|c|c|c|c|}
\hline $\begin{array}{c}\text { Variable } \\
\text { classification }\end{array}$ & Symbol & Meaning & Formula \\
\hline \multicolumn{4}{|c|}{ Explanatory variables } \\
\hline \multirow{4}{*}{$\begin{array}{c}\text { Basic } \\
\text { variables }\end{array}$} & $\mathrm{TT}$ & Total asset turnover & Sales revenue/Total Assets \\
\hline & Cost & Main business cost margins & Main business cost/Sales revenue \\
\hline & LR & Long-term liability rate & Non current liability/Total Assets \\
\hline & $\overline{F e}$ & $\begin{array}{l}\text { The financing efficiency of } \\
\text { the neighbor enterprises }\end{array}$ & $\left(\sum_{j=1}^{n} \operatorname{Size}_{j t}-\operatorname{Size}_{i t}\right) /(n-1)$ \\
\hline \multirow[t]{2}{*}{$\begin{array}{l}\text { Core va- } \\
\text { riables }\end{array}$} & $\overline{\text { Size }}$ & $\begin{array}{c}\text { The enterprise scale of the } \\
\text { neighbor enterprises }\end{array}$ & $\left(\sum_{j=1}^{n} F e_{j t}-F e_{i t}\right) /(n-1)$ \\
\hline & $\overline{R \& D}$ & $\begin{array}{c}\text { The technological } \\
\text { innovation of the neighbor } \\
\text { enterprises }\end{array}$ & $\left(\sum_{j=1}^{n} R \& D_{j t}-R \& D_{i t}\right) /(n-1)$ \\
\hline \multirow{2}{*}{$\begin{array}{l}\text { Control } \\
\text { variables }\end{array}$} & Ownership & enterprise ownership & $\begin{array}{l}\text { Dummy variable, State-owned enterprise is } \\
\qquad 1, \text { the others is } 0\end{array}$ \\
\hline & Year & enterprise age & Study year - Business year +1 \\
\hline \multicolumn{4}{|c|}{ Explained variable } \\
\hline $\begin{array}{l}\text { Explained } \\
\text { variable }\end{array}$ & $\mathrm{Fe}$ & $\begin{array}{l}\text { The financing } \\
\text { efficiency of SMEs }\end{array}$ & ROI/WACC Ratio \\
\hline
\end{tabular}


rage of the enterprise scale of the neighbor enterprises is increased by about $1 \%$, and the financing efficiency of SMEs is decreased by about $0.597 \%$ from the regression (3). This means that there is a negative correlation between the enterprise scale of the neighbor enterprises and the financing efficiency of SMEs, that is, this paper verifies the hypothesis 2. Although Jalilvand and Harris et al. think that enterprise which has a relatively large scale has small problems in the asymmetric information and agency and has a inherent advantage in long term debt market, this paper finds that there is a negative correlation between the the enterprise scale of the neighbor enterprise and the financing efficiency of SMEs. This paper thinks that there are two reasons. On the one hand, if the enterprise scale is large, the total assets turnover of SMEs would decrease. This means that the operating efficiency of SMEs using of funds raised by enterprises is poor. Therefore, the financing efficiency of SMEs is not high. On the other hand, the return on investment of SMEs will decrease with the increase of the enterprise scale. And Li Zhi-gang et al. [22] thinks that the return on investment of SMEs is negatively correlated with the financing efficiency of SMEs.

To summarize, there is a negative correlation between the enterprise scale of the neighbor enterprises and the financing efficiency of SMEs.

\subsection{Empirical Evidence for the Hypothesis 3}

According to the regression results of Table 1, this paper can find that the average of the technological innovation of the neighbor enterprises is increased by about $1 \%$, and the financing efficiency of SMEs is increased by about $0.2 \%$ from the regression (1). This means that there is a positive correlation between the technological innovation of the neighbor enterprises and the financing efficiency of SMEs, that is, this paper verifies the hypothesis 3. Yifu Lin, Li Yongjun and Zhang Jie [23] [24] find that the imperfection of financial system is the root cause of financing difficulties of SMEs in China, to solve the financing difficulties of SMEs in China, we should improve the financial system. The study which are represented by Lucas [25] shows that the economic development can promote the improvement of financial system. Domestic scholars such as Fu Jiaji, Cheng Yuan (1999) [26] find that the technological innovation can promote economic growth. Further research shows that R \& D investment costs are positively correlated with economic growth.

To summarize, there is a positive correlation between the technological innovation of the neighbor enterprises and the financing efficiency of SMEs.

\subsection{Empirical Evidence for the Hypothesis 4}

Based on the above empirical analysis, the conclusion is that there is a certain relationship between the financing efficiency of SMEs and the neighbor enterprises. However, this paper wants to know that which relationship would be more significant, the same industry or the non trade. For this reason, this paper carries out the the following study. And the regression results are shown in the following Table 3 for the model (2) and model (3). 
Table 2. The mixed OLS regression results of the basic model (1).

\begin{tabular}{|c|c|c|c|c|c|}
\hline & Variable & Regression 1 & Regression 2 & Regression 3 & Regression 4 \\
\hline \multirow{8}{*}{ Basic variables } & \multirow{2}{*}{$T T$} & $1.375^{\star * *}$ & $1.338^{\star * *}$ & $1.438^{\star * *}$ & $1.532^{\star * *}$ \\
\hline & & (143.33) & (139.83) & (155.52) & $(160.00)$ \\
\hline & \multirow{2}{*}{ Cost } & $-0.220^{* * *}$ & $-0.231^{\star * *}$ & $-0.248^{\star * *}$ & $-0.247^{\star * \star}$ \\
\hline & & $(-41.40)$ & $(-43.69)$ & $(-45.19)$ & $(-44.64)$ \\
\hline & \multirow{2}{*}{$L R$} & $-1.824^{\star * *}$ & $-1.770^{\star * *}$ & $-1.965^{\star * *}$ & $-1.790^{* * *}$ \\
\hline & & $(-32.28)$ & $(-31.80)$ & $(-33.82)$ & $(-30.61)$ \\
\hline & $\bar{\Gamma}$ & $0.510^{* * *}$ & $0.460^{* * *}$ & & \\
\hline & $\mathrm{Fe}$ & $(47.38)$ & $(58.87)$ & & \\
\hline \multirow{4}{*}{ Core variables } & \multirow{2}{*}{$\overline{\text { Size }}$} & $-0.0616^{\star * *}$ & & $-0.597^{\star \star \star}$ & \\
\hline & & $(-3.31)$ & & $(-43.48)$ & \\
\hline & \multirow{2}{*}{$\overline{R \& D}$} & $0.200^{* * *}$ & & & $0.0331^{* * *}$ \\
\hline & & $(32.22)$ & & & $(5.01)$ \\
\hline \multicolumn{2}{|c|}{ YearD } & YES & YES & YES & YES \\
\hline \multicolumn{2}{|c|}{ Ownership } & YES & YES & YES & YES \\
\hline \multirow{2}{*}{\multicolumn{2}{|c|}{ _cons }} & $-3.592^{* * *}$ & $-6.500^{* * *}$ & $-5.759^{* * *}$ & $-11.21^{\star * *}$ \\
\hline & & $(-24.65)$ & $(-75.07)$ & $(-43.50)$ & $(-182.00)$ \\
\hline \multicolumn{2}{|c|}{$\operatorname{Adj} R^{2}$} & 0.4237 & 0.4150 & 0.3988 & 0.3740 \\
\hline \multicolumn{2}{|c|}{$N$} & 117012 & 117012 & 117012 & 117012 \\
\hline
\end{tabular}

Note: $\mathrm{t}$ statistic in parentheses. ${ }^{*} \mathrm{p}<0.1,{ }^{* *} \mathrm{p}<0.05,{ }^{* *} \mathrm{p}<0.01$. The regression results are based on the basic model (1) by stata.

First, by comparing the regression 2 and the regression 6 in Table 2, this paper finds that when the average of the financing efficiency of the same neighbor enterprise enterprises is increased by about $1 \%$, and the financing efficiency of SMEs is increased by about $0.468 \%$, the result of the non trade neighbor enterprise is $0.414 \%$. Secondly, by comparing the regression 3 and the regression 7 in Table 2, this paper finds that when the average of the enterprise scale of the same neighbor enterprise enterprises is increased by about $1 \%$, and the financing efficiency of SMEs is decreased by about $0.561 \%$, the result of the non trade neighbor enterprise enterprises is $-0.519 \%$. Finally, by comparing the regression 4 and the regression 8 in Table 2, this paper finds that when the average of the technological innovation of the same neighbor enterprise enterprises is increased by about $1 \%$, and the financing efficiency of SMEs is increased by about $0.167 \%$, the result of the non trade neighbor enterprise enterprises is $0.025 \%$. Based on the above empirical results, this paper verifies the hypothesis 4 . As the same industry enterprises, they can have a clear division of labor and a higher similarity in production and management. Therefore, measures that are useful for productivity or management costs made by the neighbor enterprises can be imitated by SMEs in China. However, As the non trade enterprises, mutual reference among them is not strong because they are belong to different industries.

To summarize, the neighbor enterprises which are the same industry have a 
Table 3. The mixed OLS regression results of model (2) and model (3).

\begin{tabular}{|c|c|c|c|c|c|c|c|c|c|}
\hline \multirow{2}{*}{\multicolumn{2}{|c|}{ Variable }} & \multicolumn{4}{|c|}{ The same industry } & \multicolumn{4}{|c|}{ The non trade } \\
\hline & & Regression 1 & Regression 2 & Regression 3 & Regression 4 & Regression 5 & Regression 6 & Regression 7 & Regression 8 \\
\hline \multirow{4}{*}{$\begin{array}{c}\text { Basic } \\
\text { variables }\end{array}$} & $T T$ & $\begin{array}{l}1.338^{* * *} \\
(113.90)\end{array}$ & $\begin{array}{l}1.292^{* * *} \\
(110.01)\end{array}$ & $\begin{array}{l}1.400^{* * *} \\
(122.83)\end{array}$ & $\begin{array}{l}1.510^{* * *} \\
(130.88)\end{array}$ & $\begin{array}{c}1.366^{* * *} \\
(89.29)\end{array}$ & $\begin{array}{c}1.322^{* * *} \\
(87.18)\end{array}$ & $\begin{array}{c}1.420^{* * *} \\
(96.94)\end{array}$ & $\begin{array}{c}1.508^{* * *} \\
(98.88)\end{array}$ \\
\hline & Cost & $\begin{array}{c}-0.232^{* * *} \\
(-34.79)\end{array}$ & $\begin{array}{l}-0.247^{* * *} \\
(-37.05)\end{array}$ & $\begin{array}{c}-0.266^{* * *} \\
(-38.40)\end{array}$ & $\begin{array}{l}-0.263^{* * *} \\
(-37.61)\end{array}$ & $\begin{array}{c}-0.179^{* * *} \\
(-23.23)\end{array}$ & $\begin{array}{c}-0.188^{* * *} \\
(-24.44)\end{array}$ & $\begin{array}{c}-0.198^{* * *} \\
(-25.10)\end{array}$ & $\begin{array}{c}-0.191^{* * *} \\
(-24.23)\end{array}$ \\
\hline & $L R$ & $\begin{array}{c}-1.803^{* * *} \\
(-21.10)\end{array}$ & $\begin{array}{c}-1.770^{* * *} \\
(-21.36)\end{array}$ & $\begin{array}{c}-1.964^{* * *} \\
(-22.19)\end{array}$ & $\begin{array}{c}-1.916^{* * *} \\
(-21.19)\end{array}$ & $\begin{array}{c}-1.526^{* * *} \\
(-13.86)\end{array}$ & $\begin{array}{c}-1.487^{* * *} \\
(-13.74)\end{array}$ & $\begin{array}{c}-1.675^{* * *} \\
(-14.16)\end{array}$ & $\begin{array}{c}-1.570^{* * *} \\
(-14.19)\end{array}$ \\
\hline & $\overline{F e}$ & $\begin{array}{c}0.550^{* * *} \\
(43.79)\end{array}$ & $\begin{array}{c}0.468^{* * *} \\
(48.41)\end{array}$ & & & $\begin{array}{c}0.475^{* * *} \\
(30.16)\end{array}$ & $\begin{array}{c}0.414^{* * *} \\
(35.53)\end{array}$ & & \\
\hline \multirow[t]{2}{*}{$\begin{array}{c}\text { Basic va- } \\
\text { riables }\end{array}$} & $\overline{\text { Size }}$ & $\begin{array}{c}0.157^{* * *} \\
(6.54)\end{array}$ & & $\begin{array}{c}-0.561^{* * *} \\
(-29.45)\end{array}$ & & $\begin{array}{c}-0.0830^{* *} \\
(-3.26)\end{array}$ & & $\begin{array}{c}-0.519^{* * *} \\
(-26.86)\end{array}$ & \\
\hline & $\overline{R \& D}$ & $\begin{array}{c}0.242^{* * *} \\
(29.74)\end{array}$ & & & $\begin{array}{c}0.167^{* * *} \\
(20.08)\end{array}$ & $\begin{array}{c}0.212^{* * *} \\
(23.48)\end{array}$ & & & $\begin{array}{c}0.0253^{* *} \\
(2.71)\end{array}$ \\
\hline \multicolumn{2}{|c|}{ YearD } & YES & YES & YES & YES & YES & YES & YES & YES \\
\hline \multicolumn{2}{|c|}{ Ownership } & YES & YES & YES & YES & YES & YES & YES & YES \\
\hline \multicolumn{2}{|c|}{ _Cons } & $\begin{array}{c}-4.788^{* * *} \\
(-26.47)\end{array}$ & $\begin{array}{c}-6.368^{* * *} \\
(-59.52)\end{array}$ & $\begin{array}{c}-6.059^{* * *} \\
(-33.15)\end{array}$ & $\begin{array}{l}-9.893^{* * *} \\
(-128.27)\end{array}$ & $\begin{array}{c}-3.692^{* * *} \\
(-16.73)\end{array}$ & $\begin{array}{c}-7.049^{* * *} \\
(-52.52)\end{array}$ & $\begin{array}{c}-6.597^{* * *} \\
(-34.93)\end{array}$ & $\begin{array}{l}-11.45^{* * *} \\
(-128.41)\end{array}$ \\
\hline \multicolumn{2}{|c|}{$\operatorname{Adj} R^{2}$} & 0.3887 & 0.3782 & 0.3582 & 0.3423 & 0.4363 & 0.4250 & 0.4111 & 0.3866 \\
\hline \multicolumn{2}{|l|}{$N$} & 73554 & 73554 & 73554 & 73554 & 43458 & 43458 & 43458 & 43458 \\
\hline
\end{tabular}

Note: $\mathrm{t}$ statistic in parentheses. ${ }^{*} \mathrm{p}<0.1,{ }^{* *} \mathrm{p}<0.05,{ }^{* * *} \mathrm{p}<0.01$. The regression results are based on the basic model (1) by stata.

great more relationship with the financing efficiency of SMEs than the neighbor enterprises which are the non trade.

\section{Conclusion and Advice}

This paper studies the problem of the relationship between the "heterogeneity" of the neighbor enterprise and the financing efficiency of SMEs in china from the perspective of geographical proximity. And this paper draws the following conclusions.

Firstly, not only does the financing efficiency of SMEs has relations with their factor endowments that include the Total Assets Turnover, the Long-term liability rate, the main business cost margins, etc, but also has relations with the heterogeneity of neighbor enterprises. The financing efficiency of SMEs in china has a positive correlation with the financing efficiency and the technological innovation of the neighbor enterprises. And the financing efficiency of SMEs in china has a negative correlation with the enterprise scale of the neighbor enterprises.

Secondly, this paper finds that the neighbor enterprises which are the same industry have a great more relationship with the financing efficiency of SMEs than the neighbor enterprises which are the non trade.

According to the above study, this paper has the following theoretical and practical significance. The theoretical significance is that this paper enriches the view of the research on the financing efficiency of small and medium sized en- 
terprises. Most of the previous studies focus on their own endowments, but this paper studies the financing efficiency of SMEs in China from the perspective of environmental externalities. The practical significance mainly reflects in the following three aspects. Firstly, in China, the local government should try their best to encourage some companies to explore the suitable financing mode and to support their financing needs. And the local government should make some companies become the vanguard of improving the financing efficiency and gradually lead other companies to jointly improve the financing efficiency. What's more, the local government needs to encourage enterprises to take the road of independent innovation, fully mobilize all elements that are useful to innovation and improve the protection system of the intellectual property. So SMEs in China can promote the rapid development of the local economy so that the local financial system is more improved. As a result, it can expand the financing channels of SMEs in China. Last but not least, the local government should pay full attention to the promotion of professional enterprise cluster to economic development.

\section{References}

[1] He, Z. and Zhao, W. (2003) Characteristics of Soil Moisture of Different Vegetation Types in Initial Stage of Fixed Sand Dune of Semi-arid Region. Journal of Soil Water Conservation, 17, 164-167.

[2] Cao, J. (2004) The Application of Landscape Heterogeneity and Diversity in Urban Landscape Planning. Journal of Continuing Higher Education, 17, 45-48.

[3] Zhao, Z. and Lv, Z. (2009) A Survey on Determinants of Export Behavior Based on Heterogeneous-Firms Trade Theory. Journal of International Trade, 9, 123-128.

[4] Jing, Y. and Lu, N. (2013) A Study of Heterogeneity of Self-Esteem in College Students with Symptoms of Personality Disorders. Chinese Journal of Clinical Psychology, 21, 422-425.

[5] Wang, Z., Sun, L. and Shi, J. (2008) Heterogeneous Impacts of FDI Spillovers on the Productivity of Chinese Private Firms: Evidence from Census Data. China Economic Quarterly, 8, 129-158.

[6] Cassar, A. and Nicolini, R. (2003) Spillovers and Growth in a Local Interaction Model. Annals of Regional Science, 42, 291-306.

https://doi.org/10.1007/s00168-007-0159-x

[7] Patrick, H.T. (1966) Financial Development and Economic Growth in Developed Countries. Economic Development and Cultural Change, 88, 174-189. https://doi.org/10.1086/450153

[8] Liu, K. and Wang, L. (2010) Research on the External Financing Efficiency of SMEs in Industrial Clusters. Modern Economic Science, 32, 11-19.

[9] Wang, X. and Tang, Z. (2013) Credit Decision-Making of SMEs: Discrimination, Rationality or Cognitive Gap. Journal of Finance and Economics, 39, 99-109.

[10] Helsley, R.W. and Strange, W.C., (2007) Urban Interactions and Spatial Structure. Journal of Economic Geography, 7, 119-138. https://doi.org/10.1093/jeg/lbl027

[11] Jalilvand, A. and Harris, R.S. (1984) Corporate Behavior in Adjusting to Capital Structure and Dividend Targets: An Econometric Study. Journal of Finance, 39, 127-145. https://doi.org/10.1111/j.1540-6261.1984.tb03864.x 
[12] Wei, K. (2001) Fuzzy Analysis of the Financing Efficiency of SMEs. Journal of Finance Research, 6, 67-74.

[13] Solow, R.M. (1957) Technical Change and the Aggregate Production Function. Review of Economics \& Statistics, 39, 554-562. https://doi.org/10.2307/1926047

[14] Liu, H. and Yao, Y. (2008) Empirical Study on the Efficiency of Technology Innovation and Economic Growth in China. Statistics and Decision, 13, 101-104.

[15] Li, Z. and Xu, W. (2011) Regional Science and Technology Innovation and Economic Growth, An Empirical Analysis On Panel Data of Provinces. Science \& Technology and Economy, 24, 20-24.

[16] Bo, W. (2007) Externalities and Industrial Economic Growth-Evidence from Chinese Panel Data. China Industrial Economy, 1, 37-44.

[17] Zhao, J. and Zeng, G. (2009) Specialization, Diversification and Industrial Growth: A Case of the Central Plains Urban Agglomeration. Inquiry into Economic Issues, 8, 18-22.

[18] Wang, Z., Ma, C., Wang, Y. and Weng, G. (2003) A Geographical Investigation Into Knowledge Spillovers Between Regions. Acta Geographica Sinica, 58, 773-780.

[19] M. Funke, Niebuhr, A. (2005) Regional Geographic Research and Development Spillovers and Economic Growth: Evidence from West Germany. Regional Studies, 39, 143-153. https://doi.org/10.1080/0034340052000321904

[20] Kang, J. and Wang, N. (2007) Analysis on Financing Effect of SMEs Clusters. Industrial Technology \& Economy, 26, 64-66.

[21] Wei, S., Liu, G. and Shao, D. (2002) A Research on the Characteristics and Measures of Small and Medium-Sized Enterprises' Financing in Industrial Clusters. The Study of Finance and Economics, 28, 53-60.

[22] Li, Z., Chi, X., and Mu, C. (2008) Empirical Analysis on Financing Efficiency of SMEs. Industrial Technology \& Economy, 27, 64-66.

[23] Lin, Y., Li, Y. (2001) Promoting the Growth of Small and Medium-Sized Enterprises through the Development of Small and Medium-Sized Financial Institutions. Economic Research Journal, 1, 10-18.

[24] Zhang, J. (2002) Relationship Leading to Small Business and the Bank Organizational Structure. Economic Research Journal, 6, 32-37.

[25] Lucas, R.E. (1988) On the Mechanics of Economic Development. Journal of Monetary Economics, 22, 3-42. https://doi.org/10.1016/0304-3932(88)90168-7

[26] Fu, J. and Cheng, Y. (1999) Technological Innovation of Enterprises: the Basis and Key of Promoting Knowledge Economy. Modern Management Science, 5, 4-5. 
Submit or recommend next manuscript to SCIRP and we will provide best service for you:

Accepting pre-submission inquiries through Email, Facebook, LinkedIn, Twitter, etc. A wide selection of journals (inclusive of 9 subjects, more than 200 journals)

Providing 24-hour high-quality service

User-friendly online submission system

Fair and swift peer-review system

Efficient typesetting and proofreading procedure

Display of the result of downloads and visits, as well as the number of cited articles Maximum dissemination of your research work

Submit your manuscript at: http://papersubmission.scirp.org/

Or contact ojapps@scirp.org 